\title{
Studies on the mechanism of improved glucose control during regular exercise in Type $\mathbf{2}$ (non-insulin-dependent) diabetes
}

\author{
S. H. Schneider ${ }^{1}$, L.F. Amorosa ${ }^{1}$, A. K. Khachadurian ${ }^{1}$ and N. B. Ruderman ${ }^{2}$ \\ ${ }^{1}$ Division of Endocrinology, Metabolism and Nutrition, University of Medicine and Dentistry of New Jersey, Rutgers Medical School, \\ New Brunswick, New Jersey, and '2Department of Medicine, Boston University Medical Center, Boston, Massachusetts, USA
}

\begin{abstract}
Summary. The effects of 6 weeks of thrice weekly training on glycaemic control were assessed in 20 sedentary Type 2 (noninsulin-dependent) diabetic patients and 11 control subjects matched for previous physical activity. Maximal oxygen uptake was lower in the diabetic patients than in control subjects before training (26.2 \pm 1.1 versus $32.6 \pm 1.7 \mathrm{ml} \cdot \mathrm{kg}^{-1} \cdot \mathrm{min}^{-1}$; $p<0.001$ ). Glycosylated haemoglobin levels decreased in the diabetic patients during the training programme $(12.2 \pm 0.5$ to $10.7 \pm 0.4 \% ; p<0.02)$. Oral and intravenous glucose tolerance determined $72 \mathrm{~h}$ after the last exercise period showed only minimal improvement. Plasma glucose levels were, however,
\end{abstract}

significantly lower at $12 \mathrm{~h}$ than $72 \mathrm{~h}$ after exercise in eight subjects tested at both time points. These data suggest that an exercise programme can produce a significant decrease in glycosylated haemoglobin levels in Type 2 diabetic males probably due, in great measure, to the cumulative effect of transient improvements in glucose tolerance which follow each individual period of exercise.

Key words: Exercise, Type 2 diabetes, physical training, maximal oxygen uptake, exertion, insulin sensitivity.
Type 2 (non-insulin dependent) diabetes mellitus is associated with an increased morbidity and mortality from atherosclerotic and microvascular disease [1, 2]. Physical training is believed to improve a number of the factors which may predispose to these complications, including abnormalities in plasma lipids and lipoproteins [3-5], hyperglycaemia and hyperinsulinaemia [6-10]; for this reason it has been recommended in the treatment of Type 2 diabetes $[11,12]$. Despite this, information concerning the effectiveness of physical training in Type 2 diabetes is limited and it is unclear whether observed benefits are due to acute effects of exercise or to improved physical fitness. Likewise the optimal frequency, duration, and intensity of training sessions and the specific risks of exercise in Type 2 diabetes are uncertain.

We have assessed the effects of physical training on a group of 20 Type 2 diabetic patients and 11 control subjects matched for age, weight and previous physical activity. This study describes the effects of 6 weeks of moderately intense training on glucose tolerance, glycosylated haemoglobin $\left(\mathrm{HbA}_{1}\right)$ and plasma insulin.

\section{Subjects and methods}

\section{Subjects}

All patients were sedentary males within $20 \%$ of ideal body weight according to the Metropolitan Life Insurance tables and had Type 2 dia- betes according to the criteria of the National Diabetes Data Group [13]. None had a history or physical findings suggestive of cardiovascular, pulmonary or renal disease, hypertension or peripheral vascular insufficiency. All were treated by diet alone and none was receiving medication known to affect glucose tolerance.

Age-, sex- and weight-matched control subjects, with normal glucose tolerance by the above criteria, were also studied. Their athletic histories, i.e. participation in team sports and recreational physical activity performed at least once a week over the decade before entry to the programme were similar to those of the patients and, like the patients, none engaged in an occupation requiring heavy physical activity during the year preceding the study.

Individuals with a weight gain or loss of more than $2.5 \mathrm{~kg}$ in the preceding 6 months were excluded. All subjects were placed on a weight-maintaining diet providing $50 \%-60 \%$ of calories as carbohydrate, $15 \%$ as protein and $25 \%-35 \%$ as fat for at least 6 weeks before the initial testing and throughout the study period. Two patients and one control were cigarette smokers and maintained this habit throughout.

All studies were approved by the Institutional Review Board of Rutgers Medical School and written informed consent was obtained from each subject prior to participation.

\section{Evaluation of subjects}

All subjects were studied before and after 6 weeks of physical training. Maximal oxygen uptake $\left(\mathrm{VO}_{2} \max \right)$ was determined after they had the opportunity to become familiar with the laboratory equipment and personnel. All patients and control subjects reported to the exercise laboratory at $08.00 \mathrm{~h}$, following a $10-12 \mathrm{~h}$ overnight fast. A standard graded exercise test with ECG monitoring was performed on a Monarch bicycle ergometer (Quinton Instruments, Seattle, Washington). The exercise test consisted of a 5-min warm-up period at a workload of $25 \mathrm{~W}$, followed by increments of $25 \mathrm{~W}$ at 3-min inter- 
vals until voluntary exhaustion. A second session took place 7-10 days following the initial test. At the second visit, patients started exercise at $50 \%$ of their previously estimated $\mathrm{VO}_{2} \max$ and worked to voluntary exhaustion as before.

Expired gas was collected over the last $60 \mathrm{~s}$ of each work level and allowed to equilibrate to room temperature. Oxygen concentration was determined by an Applied Electronics oxygen meter (Applied Electrochemistry, Sunnyvale, California) and carbon dioxide concentration by a Godart-Statham Capnograph carbon dioxide meter (Godart-Statham, Bilthoven, The Netherlands). The criterion for $\mathrm{VO}_{2}$ $\max$ was a plateau of $\mathrm{VO}_{2}$ in the face of an increasing absolute work load.

Evaluation of the autonomic nervous system was performed on two occasions before training by evaluating beat to beat variation of heart rate during five deep breaths. A variation of $<10$ beats $/ \mathrm{min}$ was considered evidence of autonomic dysfunction [14].

$\mathrm{HbA}_{1}$ was measured after an overnight fast on three occasions one week apart before training. During training, $\mathrm{HbA}_{1}$ was determined at the end of weeks 5 and 6 and once during the first post-training week. During and following training, $\mathrm{HbA}_{1}$, oral and IV glucose tolerance were determined $72 \mathrm{~h}$ after the last period of exercise.

Oral glucose tolerance tests were performed at $08.00 \mathrm{~h}$, following a $10-12 \mathrm{~h}$ overnight fast. Subjects ingested $100 \mathrm{~g}$ of glucose as Glucola (R) (Ames Division, Miles Laboratories, Elkhart, Indiana) and blood was obtained at $0,30,60$, and $120 \mathrm{~min}$. Every subject was tested before and after 6 weeks of training. IV glucose tolerance tests were performed within $7-10$ days of the oral tests at $08.00 \mathrm{~h}$, following an overnight fast. Subjects received an IV dose of glucose $(0.375 \mathrm{~g} / \mathrm{kg}$ body weight) and blood samples were obtained at $0,2,4,6,10,20,30,45$ and $60 \mathrm{~min}$.

Eight diabetic patients who, after the initial 6-week training period, exercised twice a week for at least 3 months to maintain their improved $\mathrm{VO}_{2} \max$ (data not shown), were studied both 12 and $72 \mathrm{~h}$ following an exercise bout. The subjects first exercised for $30 \mathrm{~min}$ at their usual training intensity ( $70 \%$ of initial $\mathrm{VO}_{2}$ max) on a bicycle ergometer at $08.00 \mathrm{~h}$. They then remained sedentary for $72 \mathrm{~h}$ and an oral glucose tolerance test was performed. That same evening at 19.00 to

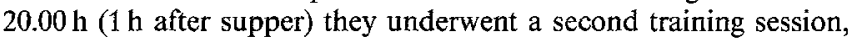
identical to the first. A second glucose tolerance test was performed the next morning approximately $12 \mathrm{~h}$ after exercise.

\section{Training}

All subjects underwent 6 weeks of physical training in the exercise laboratory under the direct supervision of the exercise physiologist. Three times a week, they exercised major muscle groups on metered equipment (bicycles, arm ergometers, treadmills, rowing machines, etc.) for eight $4-\mathrm{min}$ periods interrupted by $1.5 \mathrm{~min}$ of rest. The intensity of the work was set at $50 \%$ of $\mathrm{VO}_{2}$ max initially and was increased to $70 \%-75 \%$ of initial $\mathrm{VO}_{2}$ max over the first 2 weeks. Exercise was prescribed and monitored on the basis of heart rate. The appropriate heart rate was estimated from the determination of $\mathrm{VO}_{2} \max$ and confirmed on a subsequent day by determining the oxygen uptake during work at the prescribed rate. Following the successful completion of 6 weeks of training, glucose tolerance, $\mathrm{VO}_{2} \max$ and other measurements were repeated. Every subject attended all three sessions each week.

\section{Methods of analysis}

$\mathrm{HbA}_{1}$ was determined by ion exchange chromatography (Bio-Rad Laboratories, Richmond, California) [15]. Plasma glucose was measured enzymatically [16] and insulin was determined by radioimmunoassay (Pharmacia Diagnostics, Piscataway, New Jersey, USA) [17]. Samples obtained before and after 6 weeks of training were stored at $-20^{\circ} \mathrm{C}$ and determinations were carried out in the same assay for each subject. For IV glucose tolerance, the rate of blood glucose disappearance $\left(K_{g}\right)$ was determined from the slope of the linear regression of the log of blood glucose between 10 and $60 \mathrm{~min}$ after glucose injection [18]. To analyse further the insulin response to IV glucose, the baseline value of insulin was subtracted from the values at subsequent time points and the sum of these differences was used to reflect the area under the curve. The values from 0 to $10 \mathrm{~min}$ were used to estimate the early insulin response and the values between 10 and $60 \mathrm{~min}$ the late response [18]. Body fat was estimated using a Lange skinfold caliper (Cambridge Scientific Industries, Cambridge, Maryland, USA). Measurements were made at the biceps, triceps, supra-iliac, and subscapular areas and the sum of these measurements was used to estimate body density and percentage body fat $[19,20]$.

\section{Statistical analysis}

Measurements obtained at entry and at later visits were entered into an IBM 370/168 computer and analyzed using Statistical Analysis Systems [21]. Inter-group and intra-group comparisons were performed using analysis of variance or, where appropriate, the paired or unpaired Student's t-test. Pearson's correlation coefficients were determined to establish relationships between variables. Results are expressed as mean \pm SEM.

\section{Results}

\section{Clinical characteristics}

Work and recreational histories were similar in control and diabetic subjects. Estimated percentage body fat was also comparable between the two groups (Table 1). Two of the 20 patients had background retinopathy detected by direct ophthalmoscopy and 11 had symmetrical loss of distal vibratory and temperature sensation over the lower extremities. None of the patients complained of impotence, and blood pressure changes from lying to standing were $<10 \mathrm{mmHg}$ in all subjects. An $\mathrm{R}-\mathrm{R}$ interval variation of $<10$ beats/min was found in four of the 20 diabetic patients, all of whom also had sensory neuropathy. Neurological abnormalities were not found in any control subjects. Body weight and estimated percentage body fat were not altered by training in either group.

\section{$\mathrm{VO}_{2} \max$}

The diabetic patients initially had a significantly lower $\mathrm{VO}_{2}$ max than the control subjects $(26.2 \pm 1.1$ versus $32.6 \pm 1.7 \mathrm{ml} \cdot \mathrm{kg}^{-1} \cdot \mathrm{min}^{-1} ; p<0.001$, Table 1 ). This was not related to the slightly older age of the diabetic patients. Even when the eight oldest patients were eliminated to equalize the mean age of the two groups $(48 \pm 1$ versus $46 \pm 4$ years), the difference in $\mathrm{VO}_{2}$ max persisted $\left(25.6 \pm 1.3\right.$ versus $\left.32.6 \pm 1.7 \mathrm{ml} \cdot \mathrm{kg}^{-1} \cdot \mathrm{min}^{-1} ; p<0.001\right)$. No association was apparent between $\mathrm{VO}_{2}$ max and abnormal $\mathrm{R}-\mathrm{R}$ interval variation. A significant increase in $\mathrm{VO}_{2} \max$ and a decrease in heart rate at the same absolute submaximal workload $(100 \mathrm{~W})$ was observed in both groups after 6 weeks of physical training. The improvement in $\mathrm{VO}_{2} \max$ was less in the diabetic than the control subjects, but the difference was not statistically significant. After training the $\mathrm{VO}_{2} \max$ remained lower in the diabetic subjects. 
Table 1. Patient characteristics before and after 6 weeks of training

\begin{tabular}{|c|c|c|c|c|}
\hline & \multicolumn{2}{|c|}{$\begin{array}{l}\text { Control subjects } \\
(n=11)\end{array}$} & \multicolumn{2}{|c|}{$\begin{array}{l}\text { Diabetic patients } \\
(n=20)\end{array}$} \\
\hline & Untrained & Trained & Untrained & Trained \\
\hline Age (years) & $46 \pm 4$ & - & $51 \pm 2$ & - \\
\hline Weight (kg) & $81.6 \pm 3.1$ & $80.6 \pm 3.6$ & $78.2 \pm 1.5$ & $79.6 \pm 1.6$ \\
\hline $\begin{array}{l}\text { Estimated } \\
\text { percentage } \\
\text { body fat }\end{array}$ & $24.3 \pm 1.4$ & $24.7 \pm 1.1$ & $24.7 \pm 0.6$ & $24.4 \pm 0.6$ \\
\hline $\begin{array}{l}\mathrm{VO}_{2} \max \\
\left(\mathrm{ml} \cdot \mathrm{kg}^{-1}\right. \\
\left.\min ^{-1}\right)\end{array}$ & $32.6 \pm 1.7$ & $37.5 \pm 2.3^{c}$ & $26.2 \pm 1.1^{\mathrm{d}}$ & $28.4 \pm 1.0^{a_{1} d}$ \\
\hline $\begin{array}{l}\text { Heart rate at } \\
100 \mathrm{~W} \\
\text { (beats } / \mathrm{min} \text { ) }\end{array}$ & $132 \pm 5$ & $124 \pm 8^{b}$ & $138 \pm 4$ & $124 \pm 4^{b}$ \\
\hline
\end{tabular}

Results are expressed as mean $\pm \mathrm{SEM} . \mathrm{VO}_{2} \max$ is given for conditions of standard temperature and pressure. ${ }^{\mathrm{a}} p<0.05,{ }^{\mathrm{b}} p<0.02$, ${ }^{c} p<0.01$ for trained versus untrained subjects; ${ }^{d} p<0.01$ for diabetic versus control subjects

\section{Glycosylated haemoglobin}

Levels of $\mathrm{HbA}_{1}$ decreased significantly in the diabetic patients after 6 weeks of training, suggesting overall improvement in glucose homeostasis (Table 2). There was no significant correlation between the decrease in $\mathrm{HbA}_{1}$ and body weight, age, duration of diabetes, initial $\mathrm{VO}_{2}$ max, or improvement in $\mathrm{VO}_{2} \max$. The 13 patients with fasting plasma glucose levels $<11.1 \mathrm{mmol} / 1(200 \mathrm{mg} / \mathrm{dl})$ at entry had a threefold greater decrease in $\mathrm{HbA}_{1}$ than the patients with glucose levels $>11.1 \mathrm{mmol} / 1$, although because of patient variability the difference was not statistically significant $(1.8 \pm 0.5$ versus $0.6 \pm 0.4 \%)$.

\section{Glucose tolerance measured $72 \mathrm{~h}$ post-exercise in trained subjects}

Despite the decrease in $\mathrm{HbA}_{1}$ in the diabetic patients after 6 weeks of training, oral glucose tolerance showed only a minimal improvement, which attained statistical significance only at $30 \mathrm{~min}$. A similar pattern was seen in the control subjects. As a group, the diabetic patients had modest fasting hyperinsulinaemia. However, their insulin response to oral glucose was impaired and did not change after 6 weeks of training (Table 3).

Training appeared to result in a small improvement in IV glucose disposal but the difference did not attain statistical significance in either group. The diabetic patients had a severe deficiency in the early insulin response $(0-10 \mathrm{~min})$ to IV glucose, but the late response (10-60 min) was similar to controls. Training had little effect on these insulin levels in the diabetic patients while in the control subjects the early insulin response tended to decrease, while late insulin responses were enhanced (Table 4).
Table 2. Effect of physical training on glycosylated haemoglobin

\begin{tabular}{lll}
\hline & \multicolumn{2}{l}{ Glycosylated haemoglobin $\mathrm{A}_{1}(\%)$} \\
\cline { 2 - 3 } & $\begin{array}{l}\text { Control subjects } \\
(n=11)\end{array}$ & $\begin{array}{l}\text { Diabetic patients } \\
(n=20)\end{array}$ \\
\hline Untrained & $7.7 \pm 0.2$ & $12.2 \pm 0.5$ \\
Trained & $7.5 \pm 0.2$ & $10.7 \pm 0.4^{\mathrm{a}}$ \\
\hline
\end{tabular}

Results are expressed as mean \pm SEM. Measurements were carried out before and after training three times a week for 6 weeks. ${ }^{a} p<0.02$ for trained versus untrained subjects

Table 3. Effect of physical training on oral glucose tolerance

\begin{tabular}{|c|c|c|c|c|}
\hline \multirow[t]{2}{*}{ Time (min) } & \multicolumn{2}{|c|}{$\begin{array}{l}\text { Control subjects } \\
(n=11)\end{array}$} & \multicolumn{2}{|c|}{$\begin{array}{l}\text { Diabetic patients } \\
(n=20)\end{array}$} \\
\hline & Untrained & Trained & Untrained & Trained \\
\hline \multicolumn{5}{|c|}{ Glucose $(\mathrm{mmol} / \mathrm{l})$} \\
\hline 0 & $5.3 \pm 0.2$ & $5.1 \pm 0.2$ & $9.9 \pm 0.5$ & $9.6 \pm 0.6$ \\
\hline 30 & $9.7 \pm 0.6$ & $7.9 \pm 0.3^{\mathrm{a}}$ & $14.4 \pm 0.6$ & $12.8 \pm 0.7^{\mathrm{a}}$ \\
\hline 60 & $8.3 \pm 0.8$ & $7.8 \pm 0.4$ & $17.8 \pm 0.6$ & $16.5 \pm 0.8$ \\
\hline 120 & $6.1 \pm 0.4$ & $6.1 \pm 0.4$ & $18.7 \pm 0.9$ & $18.0 \pm 0.9$ \\
\hline \multicolumn{5}{|c|}{ Insulin $(\mathrm{mU} / \mathrm{l})$} \\
\hline 0 & $13 \pm 2$ & $10 \pm 1$ & $16 \pm 2$ & $16 \pm 2^{c}$ \\
\hline 30 & $47 \pm 9$ & $56 \pm 11$ & $30 \pm 4^{b}$ & $28 \pm 3^{c}$ \\
\hline 60 & $56 \pm 8$ & $57 \pm 6$ & $39 \pm 5$ & $39 \pm 4^{b}$ \\
\hline 120 & $47 \pm 7$ & $45 \pm 7$ & $42 \pm 4$ & $51 \pm 5$ \\
\hline
\end{tabular}

Results are expressed as mean \pm SEM. Glucose tolerance tests were performed $72 \mathrm{~h}$ after the last training session. ${ }^{a} p<0.05$ trained versus untrained subjects; ${ }^{b} p<0.02,{ }^{c} p<0.01$; diabetic versus control subjects

Table 4. Effect of physical training on IV glucose tolerance

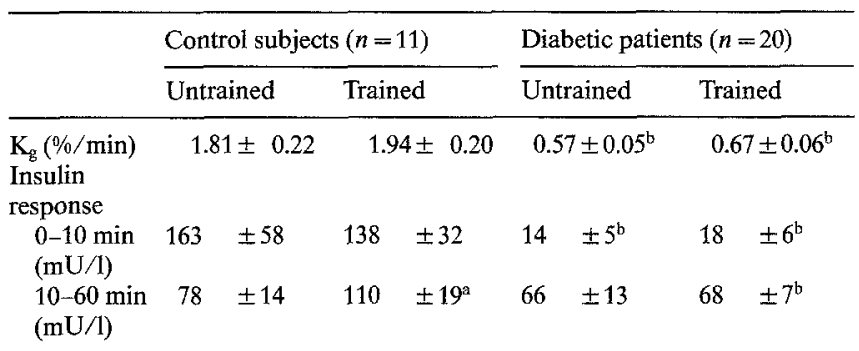

Results are expressed as mean \pm SEM. Tests were performed $72 \mathrm{~h}$ af ter an exercise session. $\mathrm{K}_{\mathrm{g}}$ was calculated from the slope of linear regression of the log of glucose concentration between 10-60 min after the glucose injection. Values for the insulin response were obtained by subtracting the insulin concentration at time 0 from those at subsequent times and adding the differences. ${ }^{a} p<0.02$; trained versus untrained subjects; ${ }^{b} p<0.01$; diabetic versus control subjects

Table 5. Comparison of oral glucose tolerance 12 and $72 \mathrm{~h}$ post-exercise in eight trained diabetic subjects

\begin{tabular}{rll}
\hline Time (min) & \multicolumn{2}{l}{ Plasma glucose $(\mathrm{mmol} / 1)$} \\
\cline { 2 - 3 } & $12 \mathrm{~h}$ & $72 \mathrm{~h}$ \\
\hline 0 & $10.0 \pm 1.1$ & $11.2 \pm 1.1^{\mathrm{a}}$ \\
30 & $13.3 \pm 1.5$ & $15.1 \pm 1.3^{\mathrm{a}}$ \\
60 & $17.3 \pm 1.6$ & $18.8 \pm 1.3^{\mathrm{b}}$ \\
120 & $17.3 \pm 1.7$ & $19.2 \pm 1.4^{\mathrm{b}}$ \\
\hline
\end{tabular}

Results are expressed as mean \pm SEM. ${ }^{\mathrm{a}} p<0.05,{ }^{\mathrm{b}} p<0.02 ; 12$ versus $72 \mathrm{~h}$ 
Glucose tolerance and plasma insulin in trained individuals 12 and $72 \mathrm{~h}$ after exercise

To determine whether glucose tolerance was improved at a time earlier than $72 \mathrm{~h}$ post-exercise, oral glucose tolerance tests were performed at both 12 and $72 \mathrm{~h}$ after the last period of exercise in eight trained diabetic patients. Plasma glucose levels were significantly lower at $12 \mathrm{~h}$ at all time points (Table 5). There were no differences in plasma insulin. The four patients who showed the largest improvement at $12 \mathrm{~h}$ compared with $72 \mathrm{~h}$, had a mean fasting plasma glucose of $9.3 \pm 1.5$ versus $13.1 \pm 0.6 \mathrm{mmol} / \mathrm{l}$ for the other four subjects.

\section{Complications during training}

Two patients developed symptomatic, but transient, orthostatic hypotension following maximal exercise in the untrained state. Only one of these individuals had an abnormal R-R interval variation ( 7.6 beats $/ \mathrm{min}$ ). Six patients had asymptomatic post-exercise orthostatic hypotension. All the hypotensive episodes occurred in the summer months and it is our impression that Type 2 diabetic patients are less tolerant to exercise in warm weather. No orthostatic changes occurred in either group following training. One patient had a significant increase in background retinopathy during the study. However none experienced clinically evident visual, renal, or neurological deterioration. No patient had an episode of hypoglycaemia.

\section{Discussion}

We have studied a well-defined group of mildly obese, male Type 2 diabetic patients with moderate glucose intolerance, mild fasting hyperinsulinaemia and a sedentary lifestyle. Despite similar recreational and work histories, the diabetic patients had a lower $\mathrm{VO}_{2} \max$ than did the control subjects. While $\mathrm{VO}_{2} \max$ declines with age [22] and the diabetics were slightly older, this did not account for the difference as it persisted after correcting for this variable. Low values for $\mathrm{VO}_{2} \max$ in Type 2 diabetes have been reported previously [23, 24]; at present there is no adequate explanation for this finding. In insulin-dependent-diabetes, it has been associated with dysfunction of the autonomic nervous system $[25,26]$ but none of our patients had orthostatic hypotension and only four had a clearly abnormal R-R interval variation. However, subtle autonomic dysfunction and unappreciated differences in lifestyle or cardiac or skeletal muscle function cannot be excluded as explanations.

Training at the prescribed levels was under the direct supervision of an exercise physiologist and resulted in an increased $\mathrm{VO}_{2} \max$ and a decrease in heart rate at the same submaximal workload in both diabetic and control subjects. The diabetic patients appeared to have a smaller increment in $\mathrm{VO}_{2}$ max than controls, possibly because the intensity of the training regimen was based on an individual's initial $\mathrm{VO}_{2} \max$ and was thus lower for these subjects. Similar increases in $\mathrm{VO}_{2}$ max during training regimens of modest intensity have been reported by others [27-30].

Following 6 weeks of training there was a significant decrease in the levels of $\mathrm{HbA}_{1}$ in the diabetic patients, suggesting improvement in overall glycaemic control. It is unlikely that this improvement was the result of subtle dietary alterations. Subjects were carefully instructed on maintaining a constant diet and were given 6 weeks of dietary equilibration prior to the study. Food intake was estimated weekly by the nurse during the study and no significant changes were noted in caloric intake or diet composition. In addition, body weight and adiposity remained constant. However, maintenance of a constant weight throughout the training period suggests that a small increase in caloric intake (in the range of approximately 100 calories a day) probably occurred. It is also unlikely that exercise-induced haemolysis lowered $\mathrm{HbA}_{1}$ levels, since a similar decrease was not observed in the exercising control group, and haematocrits remained stable throughout training.

Several studies have demonstrated enhanced glucose tolerance in endurance athletes and an apparent increase of insulin sensitivity during physical training in normal and diabetic subjects [7, 8, 30-33]. Whether the improvements in glucose tolerance were the result of the summed effects of individual exercise bouts or of the trained state has not been addressed by these studies. Improved glucose disposal following a single period of exercise has been demonstrated repeatedly [6, 34 36]. Whether the duration or magnitude of this acute response is altered by training is unknown, although recent studies by Goldberg et al. [37] suggest this may be the case. Rapid deterioration of glucose tolerance following the cessation of exercise in trained individuals has also been noted [5,33,38], although changes in $\mathrm{VO}_{2}$ max and muscle enzyme profiles associated with improved fitness persist for weeks [39]. These findings are consistent with the hypothesis that much of the improvement noted in glucose disposal during physical training is related to the summed effects of individual bouts of exercise. Our studies are also consistent with this hypothesis. Thus, the improvement in $\mathrm{HbA}_{1}$ in the trained diabetic patients occurred without major alterations in adiposity. It was also unrelated to the initial $\mathrm{VO}_{2}$ max or the improvement in $\mathrm{VO}_{2} \max$ suggesting that it had little relationship to the level of fitness. Most importantly glucose tolerance was significantly better at $12 \mathrm{~h}$ than at $72 \mathrm{~h}$ after an acute period of exercise; in fact, at the latter time, it was similar to that in the pretrained state. At the practical level, these findings suggest that in Type 2 diabetes exercise of the type and intensity used here should be performed three or more times a week to achieve a continuous improvement in glycaemic control. 
Berger et al. [40] and Wahren et al. [41] have reported that exercise acutely lowers the blood glucose levels in most diabetic patients with a fasting plasma glucose concentration less than $11.1 \mathrm{mmol} / 1 \quad(200 \mathrm{mg} / \mathrm{dl})$, whereas in patients with higher fasting glucose concentrations blood glucose may increase. Fasting glucose levels prior to training tended to fall in our diabetic and normal subjects during $30 \mathrm{~min}$ of bicycle exercise at $70 \% \mathrm{VO}_{2} \max (-0.8 \pm 0.6$ versus $-0.3 \pm 0.2 \mathrm{mmol} / 1$; NS). These small changes did not correlate with improved glucose control. However, our own observation that diabetic patients with a fasting glucose level less than $11.1 \mathrm{mmol} / 1$ showed a stronger tendency to diminish their $\mathrm{HbA}_{1}$ than did diabetic patients with higher glucose levels is consistent with this concept. Similarly, the four patients showing the greatest difference between $12 \mathrm{~h}$ and $72 \mathrm{~h}$ post-exercise glucose tolerance were those with the lowest fasting plasma glucose levels. Extension and confirmation of these findings may prove useful in identifying diabetic patients particularly likely to benefit from programmes of regular exercise.

In general, the patients tolerated the exercise programme well and there were no major complications. Our observation of post-exercise orthostatic hypotension in patients without clinical evidence of autonomic neuropathy suggests the need to monitor post-exercise blood pressure in the untrained diabetic initiating an exercise programme, especially in warm weather. Physical training appears to ameliorate this problem. The relationship between post-exercise hypotension and subclinical neuropathy or myocardial disease requires further investigation.

In conclusion, the data suggest that a programme of regular physical training in Type 2 diabetes can be safely and effectively utilized as part of the overall treatment plan. Patients with milder diabetes with a fasting plasma glucose of less than $11 \mathrm{mmol} / 1$ may be particularly likely to benefit. Because the short-term improvements appear to result mainly from the summed effects of the individual bouts of exercise, the frequency of the exercise may be an important determinant of the response. Our studies were limited to male subjects and further studies should be performed to determine whether these results can be applied to female subjects.

Acknowledgement. The author wishes to thank Ms. D. Sharnak for acting as nurse coordinator, Ms. C. Runo for her technical assistance, and Mr. E.Hulihan who helped in the planning of the exercise programme and supervised the exercise sessions. This work was supported by National Institutes of Health Grant No. AM 26894.

\section{References}

1. Jarrett RJ, Keen H, Chakrabarti R (1982) Diabetes, hyperglycaemia and arterial disease. In: Keen $\mathbf{H}$, Jarrett RJ (eds) Complications of diabetes, 2nd edn. Edward Arnold, London, pp 179-203

2. Kannel WB, McGee DL (1979) Diabetes and cardiovascular disease - the Framingham Study. JAMA 241: 2035-2038
3. Wood PD, Haskell WL (1979) Effect of exercise on plasma high density lipoproteins. Lipids $14: 417-427$

4. Wood PD, Haskell W, Klein H, Lewis S, Stern MP, Farquhar JW (1976) Distribution of plasma lipoproteins in middle aged male runners. Metabolism 25: 1249-1257

5. Ruderman NB, Ganda OP, Johansen K (1979) Effects of physical training on glucose tolerance and plasma lipids in maturity onset diabetes mellitus. Diabetes 28 (Suppl 1): 89-92

6. Maehlum S, Pruett EDR (1973) Muscular exercise and metabolism in male juvenile diabetes. Scand J Clin Lab Inv 32: 149-153

7. Lohmann D, Liebold F, Heilmann W, Stinger J, Pohl A (1978) Diminished insulin response in highly trained athletes. Metabolism 27: $521-524$

8. Bjorntorp P (1981) Effects of exercise on plasma insulin. Int J Sports Med 2: 125-129

9. Saltin B, Lindgarde F, Houston $M$, Horlin R, Nygaard E, Gad P (1978) Physical training and glucose tolerance in middle aged men with chemical diabetes. Diabetes 28: 30-32

10. Froelicher VF (1978) Exercise and the prevention of atherosclerotic heart disease. Cardiovasc Clin 9: 13-23

11. Richter EA, Ruderman NB, Schneider SH (1981) Exercise and diabetes. Am J Med 70: 201-209

12. Felig $P$ (1981) The endocrine pancreas. In: Felig P, Baxter JD, Broadus AE, Frohman LA (eds) Endocrinology and metabolism. McGraw-Hill, New York p 844

13. National Diabetes Data Group (1979) Classification and dignosis of diabetes mellitis and other categories of glucose tolerance. Diabetes 28: 1039-1057

14. Hilsted J, Jensen SB (1979) A simple test for autonomic neuropathy in juvenile diabetics. Acta Med Scand 205:385-387

15. Davis JE, McDonald JM, Jarett L (1978) Bio-Rad HbA by column test. Diabetes 27: 102-106

16. Bergmeyer HU, BerntE (1971) Determination with glucose oxidase and perioxidase. In: Bergmeyer $\mathrm{H}$ (ed) Methods of enzymatic analysis. Academic Press, New York, pp 1205-1214

17. Wide L (1969) Radioimmunoassays employing immunosorbents. Acta Endocrinol Suppl 142: 207-221

18. Fineberg SE, Schneider SH (1980) Glipizide versus tolbutamide, an open trial. Diabetologia 18: 49-54

19. Brozek JF, Kihlberg JK, Tayor HL (1963) Skinfold distributions in middle aged American men: a contribution to norms of leannessfatness. Ann NY Acad Sci 110: 492-502

20. Durnin JVGA, Rahaman MM (1967) The assessment of the amount of fat in the human body from measurements of skinfold thicknesses. Br J Nutr 21: 681-689

21. Barr AJ, Goodnight SH, Sall JP (1979) Statistical analysis systems. SAS Institute, Raleigh, North Carolina

22. Hossack KF, Bruce RA (1982) Maximal cardiac function in sedentary normal men and women: comparison of age related changes. J Appl Physiol 53: 799-804

23. Saltin B, Lindgarde F, Lithell H, Eriksson KF, Gad P (1980) Metabolic effects of long term physical training in maturity onset diabetes. In: Waldhaus1 WK (ed) Proceedings of the 10th Congress of International Diabetes Federation Vienna, Austria. Excerpta Medica, Amsterdam, pp 345-350

24. Rubler S (1981) Asymptomatic diabetic females - exercise testing. NY State J Med 81: 1185-1191

25. Storstein L, Jervell J (1979) Response to bicycle exercise testing of long standing juvenile diabetics. Acta Med Scand 205-227-230

26. Hilsted J, Galbo H, Christensen NJ (1979) Impaired cardiovascular responses to graded exercise in diabetic autonomic neuropathy. Diabetes 28: 313-319

27. Huttunen JK, Lansimies E, Voutilainen E, Ehnholm C, Hietanen F, Panttila I, Siitonen O, Rauramua R (1979) Effect of moderate physical exercise on serum lipoproteins. Circulation 60: $1220-1229$

28. Lipson LC, Bonow RW, Schaefer EJ, Brewer H, Lindgren FT (1980) Effect of exercise conditioning on plasma high density lipoprotein and other lipoproteins. Atherosclerosis 37: 529-538

29. Orlander J, Kiessling KH, Ekblum B (1980) Time course of adap- 
tations to low intensity training in sedentary men: dissociates of central and local effect. Acta Phys Scand 108: 85-90

30. Wallberg-Henriksson H, Gunnarsson R, Henriksson J, DeFronzo R, Felig P, Ostman J, Wahren J (1982) Increased peripheral insulin sensitivity and muscle oxidative enzymes but unchanged blood glucose control in Type I diabetics after physical training. Diabetes 31: 1044-1050

31. Rosenthal M, Haskell WL, Soloman R, Widstrom A, Reaven GM (1983) Demonstration of a relationship between levels of physical training and insulin stimulated glucose utilization in normal humans. Diabetes 32: 408-411

32. LeBlanc J, Nadeau A, Richard D, Tremblay A (1982) Variations in plasma glucose, insulin, growth hormone and catecholamines in response to insulin in trained and non-trained subjects. Metabolism 31: $453-456$

33. LeBlanc J, Nadeau A, Richard D, Tremblay A (1981) Studies on the sparing effect of exercise on insulin requirements in human subjects. Metabolism 30: 1119-1124

34. Fahlen M, Stenberg J, Bjorntorp P (1972) Insulin secretion in obesity after exercise. Diabetologia 8: 141-144

35. Caron D, Poursier P, Marliss EB, Zinman B (1982) The effect of postprandial exercise on meal related glucose intolerance in insulin-dependent diabetes mellitus. Diabetes Care 5: 364-369

36. Holm G, Bjorntorp P, Jagenburg R (1978) Carbohydrate, lipid and amino acid metabolism following physical exercise in man. $J$ Appl Physiol 45: 128-131

37. Skor D, Gavin J, Hagberg J, Schultz J, Santiago J, Goldberg A
(1983) Effect of acute and chronic exercise on insulin sensitivity in non-insulin dependent diabetics. Diabetes 32 (Suppl 1): 64 A

38. Gavin JR III, Heath GW, Ponser JM, Hagberg JM, Bloomfield SA, Holloszy JO (1982) Improvement in insulin sensitivity with acute exercise. Diabetes 31 (Suppl 2): $32 \mathrm{~A}$

39. Saltin B, Rowell LB (1980) Functional adaptations to physical activity and inactivity. Fed Proc 39:1506-1513

40. Berger M, Berchtold P, Cuppers HJ, Drost H, Kley HK, Muller WA, Weigelmann W, Zimmerman-Telschow H, Gries FA, Kruskemper HL, Zimmerman H (1977) Metabolic and hormonal effects of muscular exercise in juvenile type diabetes. Diabetologia 13: 355-365

41. Wahren J, Felig P, Hendler R, Ahlborg G (1973) Glucose and amino acid metabolism during recovery after exercise. J Appl Physiol 34: $838-845$

Received: 10 October 1983

and in revised form: 21 January 1984

Dr. S.H.Schneider

Department of Medicine

University of Medicine and Dentistry of New Jersey

Rutgers Medical School

Academic Health Science Center, CN 19

New Brunswick, New Jersey 08903

USA 